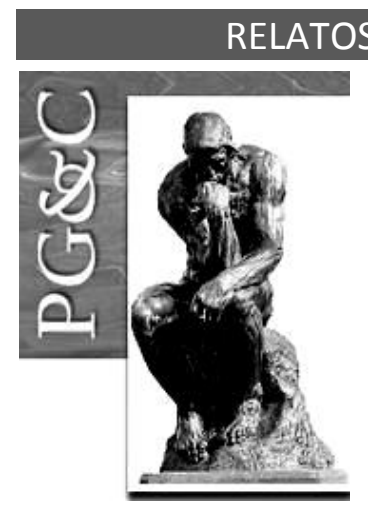

\title{
O COMÉRCIO ELETRÔNICO (E-COMMERCE): UM ESTUDO COM CONSUMIDORES
}

\author{
Marta Cleia Ferreira de Andrade \\ Mestre em Administração pela Universidade do Vale do Rio dos Sinos, \\ Brasil. Professora da Faculdade de Ciências e Educação de Rubiataba, \\ Brasil. \\ E-mail: marta.cleia@hotmail.com \\ Naiara Taiz Gonçalves da Silva \\ Graduanda em Administração pela Faculdade de Ciências e Educação de \\ Rubiataba, Brasil. \\ E-mail: naiarataizgoncalvessilva@hotmail.com
}

\begin{abstract}
Resumo
As organizações sempre buscam a competitividade, se esforçando para aprimorar seus meios de negociação e ficar por dentro de tudo que traga evolução e maior valor para os negócios. Com isso, a evolução do comércio eletrônico, que vem ocorrendo no contexto brasileiro, exige das empresas, de modo geral, agilidade e reestruturação, para que possam se manter no páreo. Portanto, este trabalho tem como objetivo identificar o posicionamento e a experiência de compra de alguns consumidores do Vale do São Patrício, em relação ao Comércio Eletrônico. Trata-se de uma região localizada no estado de Goiás. Para isso, foram aplicados 30 questionários com perguntas abertas e fechadas, nas cidades de Rubiataba e Nova América, Goiás. Os resultados deste estudo trazem as principais experiências e opiniões dos consumidores em relação às compras on-line. Destacando, entre outros, aquilo que podem ser consideradas como barreiras no processo de compra, como a falta de segurança, ainda encontrada no comércio eletrônico. Sendo que $57 \%$ dos respondentes apontaram tal fator como a barreira principal para o comércio eletrônico no Brasil. Notou-se que os preços baixos das compras on-line é fator de motivação predominante. Isto é o que mais chama a atenção dos internautas, quando decidem realizar suas compras. Além disso, há também a questão cultural que influencia, fazendo com que o consumidor não deixe de realizar suas compras em lojas físicas.
\end{abstract}

Palavras-chave: Comércio eletrônico. Internet. Consumidor

\section{E-COMMERCE: A STUDY WITH CONSUMERS}

\begin{abstract}
Organizations always seeking competitiveness, strive to improve their means of negotiation and stay on top of things that bring progress and greater business value. Thus, the evolution of e-commerce that has taken place in the Brazilian context, requires companies generally, agility and restructuring so that they can remain in the running, as the market changes. Therefore, this study aims to identify the positioning and the shopping experience of some consumers Valley St. Patrick, in relation to e-commerce. This Valley, this is a region located in the state of Goias. For this, we applied 30 questionnaires with open and closed questions in the cities of Rubiataba and New America, Goias. The results of this study bring thus the main experiences and consumer reviews regarding online shopping. Highlighting, among others, what can be considered as barriers in the buying process, such as lack of security, also found in ecommerce. With 57\% of respondents cited this factor as the main barrier to e-commerce in Brazil. It was noted that the low prices of online shopping is predominant motivating factor. This is what most draws the attention of internet users when they decide to make their purchases. In addition, there is also a cultural issue that influences the consumer to unlink of shopping in physical stores.
\end{abstract}

Keywords: E-commerce. Internet. Consumer.

Perspectivas em Gestão \& Conhecimento, João Pessoa, v. 7, n. 1, p. 98-111, jan./jun. 2017 DOI: http://dx.doi.org/10.21714/2236-417X2017v7n1p98

http://periodicos.ufpb.br/ojs2/index.php/pgc. ISSN: 2236-417X. Publicação sob Licença (cc) EY-Nc-ND 


\section{INTRODUÇÃO}

Com o desenvolvimento da tecnologia eletrônica, as empresas, de modo geral, têm passado por grandes mudanças. Hoje, a tecnologia oferece às empresas algumas vantagens, como: ganhos de eficiência, maior praticidade no atendimento ao cliente, tomada de decisão mais acertada, flexibilidade, maior dinamismo no giro do estoque, dentre outras. Todos esses fatores permitem às empresas buscar uma atuação que satisfaça às necessidades dos clientes.

Nesse contexto, se desponta a modalidade do comércio eletrônico (e-commerce), com um potencial de gerar mais vendas para as empresas e, consequentemente, mais vantagens para os consumidores, além de abrir novas possibilidades de negócios que seriam impensáveis anteriormente (DINIZ, 1999). Segundo Almeida Júnior (2007), os processos de comércio eletrônico tiveram início no território brasileiro há cinco anos. Desde então, a exemplo do que aconteceu nos Estados Unidos, esta modalidade de comércio vem ganhando espaço no território nacional.

Dessa forma, a situação atual de acesso à internet e o comportamento dos usuários vêm sendo favoráveis ao crescimento do comércio eletrônico, e assim, as oportunidades de negócios, via forma eletrônica, não se limitam às vendas diretas por meio de uma única loja virtual, mas por diversas integrações, como os serviços móveis, TV digital, Personal Digital Assistants (PDAs) e outros, dadas as oportunidades que o ambiente virtual proporciona para os usuários (SANTOS; ARRUDA FILHO, 2014).

Nesse sentido, Campi (2014) afirma que segundo os dados da E-bit (entidade que garante mais segurança nas compras eletrônicas), 51,3 milhões de pessoas no Brasil já estão utilizando a Internet, ao menos uma vez para realizarem compras. Ainda segundo Campi (2014), sua pesquisa demonstra um crescimento de $28 \%$ no comércio eletrônico, em comparação ao ano de 2013, gerando um faturamento de 28,8 bilhões de reais. Além disso, houve também um aumento de $32 \%$ nos pedidos de compras online, chegando a 88,3 milhões de reais.

Percebe-se o quanto o comércio eletrônico tem se expandido, mostrando seu potencial de gerar lucros para as empresas e valor para os consumidores. Porém, mesmo com essa perspectiva, a literatura mostra que ainda existem consumidores que não são adeptos às compras eletrônicas. Com o desenvolvimento desta modalidade de compras, emergiram também alguns riscos para o consumidor, um fator desfavorável, pois a segurança é tida como um aspecto de grande preocupação dos clientes (AZEVEDO; ODONE; COELHO, 2014).

Assim, as empresas têm esse desafio a ser enfrentado, na busca por tornar suas lojas virtuais um meio seguro de realização de compras. Esses e outros fatores precisam, portanto, de estratégias de superação, pois sabe-se que muitas pessoas ainda não realizam suas compras pela Internet, apesar das vantagens existentes.

Desse modo, todo esse contexto gerou algumas dúvidas e culminou na necessidade de aumentar o debate acerca do comércio eletrônico, tendo em vista a carência de estudos nessa área. Concordando com Diniz (1999), a aceitação ampla do mercado online necessita de pesquisas que indiquem com melhor precisão a sua evolução. Espera-se que este estudo traga uma melhor compreensão do comércio eletrônico no âmbito nacional. Com isso, buscou-se realizar uma pesquisa no contexto do Vale de São Patrício, região situada no estado de Goiás. Tem-se, portanto, a seguinte pergunta de pesquisa: quais são as opiniões, experiências e expectativas dos consumidores pesquisados, quanto ao comércio eletrônico?

Portanto, este trabalho tem o objetivo de identificar o posicionamento e a experiência de compra de alguns consumidores em relação ao comércio eletrônico, bem como destacar que fatores são tidos como oportunidades e desafios para as empresas.

Os consumidores que participaram desta pesquisa são pessoas escolhidas aleatoriamente no Vale do São Patrício. Optou-se, portanto, pela amostra não probabilística

Perspectivas em Gestão \& Conhecimento, João Pessoa, v. 7, n. 1, p. 98-111, jan./jun. 2017. 
por conveniência. Sendo assim, foi aplicado um questionário contendo perguntas abertas e fechadas, relacionadas às opiniões, experiências e expectativas dos consumidores no âmbito do comércio online. 0 público-alvo da pesquisa foi de 30 respondentes, que haviam comprado eletronicamente nos últimos seis meses, homens e mulheres, moradores das cidades de Rubiataba e Nova América, estado de Goiás.

\section{O COMÉRCIO ELETRÔNICO NO CONTEXTO BRASILEIRO}

O comércio eletrônico é consequência do aperfeiçoamento da internet. Para Nakamura (2011), em 1979, o inventor inglês Michael Aldrich inventou as compras online, utilizando uma televisão personalizada de 26 polegadas para um computador doméstico, que possuía um sistema de processamento de tempo de transação, através de linha telefônica.

O e-commerce teve início em 1995, nos Estados Unidos, com o surgimento da Amazon.com e outras empresas. E, só após cinco anos, esse setor começou a se desenvolver no Brasil. Desde então, as vendas através da internet não pararam de crescer (TOREZANI, 2008).

Hoje, os diferentes tipos de produtos e serviços chegam simultaneamente em alta velocidade ao cliente, em todo o mundo. Não há dúvidas que a internet seja a responsável por disseminar informações e mudanças, juntamente com as características do mercado da informática e sua área de programação, que são utilizadas para incentivar e ampliar o comércio pela rede.

Para Guerreiro (2006), o comércio eletrônico é uma revolução comercial, juntamente com a inovação tecnológica, permitindo que empresas sejam mais flexíveis e eficientes em suas operações, trabalhando cada vez mais próximas de seus fornecedores e sendo mais eficientes em atender as necessidades de seus clientes.

Almeida Júnior (2007) define comércio o eletrônico ou e-commerce, como um tipo de transação comercial feita especialmente através de um equipamento eletrônico, como por exemplo, por meio do computador. Complementando, para Nakamura (2011), o comércio eletrônico trata-se de todos os processos envolvidos da cadeia de valor realizada num ambiente eletrônico, utilizando de ferramentas da tecnologia da informação e de comunicação, tendo como principal objetivo atender as necessidades dos negócios.

O comércio eletrônico, mesmo sendo realizado através de meios eletrônicos, não deixa de ter alguns processos da negociação tradicional. Para Albertin (2004), o comércio eletrônico é a realização de toda a cadeia de valor dos processos de negócio, num ambiente eletrônico, através da aplicação das tecnologias de comunicação e informação, atendendo aos objetivos do negócio.

Com base nisso, no comércio eletrônico há a exposição do produto disponível para venda, através de fotos demonstrativas e um atendente virtual, para tirar as dúvidas do consumidor. Porém, as fotos ilustrativas podem não ser exatamente o produto, não sendo inteiramente confiável, e o consumidor precisa acreditar nas palavras do vendedor, o que gera muita insegurança. Pois em uma loja física, o consumidor tem acesso ao produto, pode fazer observações e tirar suas conclusões. Algo que por passar por "despercebido" ao atendente ou até mesmo ser considerado insignificativo, para o consumidor pode ser um fator de total importância (ALMEIDA JÚNIOR, 2007).

Por outro lado, a compra em lojas "físico-virtuais" acaba tendo um caráter muito mais racional, uma vez que a comparação dos produtos é feita com base em informações técnicas disponíveis e o impacto visual de uma foto não é o mesmo que o impacto visual do produto, sendo que o lado emocional pode ser também explorado. Neste tipo de loja, cabe ao vendedor encarregado transmitir parte do caráter emocional da compra, destacando os benefícios e as

Perspectivas em Gestão \& Conhecimento, João Pessoa, v. 7, n. 1, p. 98-111, jan./jun. 2017. 
qualidades dos produtos, o que pode ser particularmente explorado em função do relacionamento mais estreito que se estabelece na compra da loja "físico-virtual" (TESTA; LUCIANO, 2008).

O comércio eletrônico mostra-se que veio para facilitar a compra e venda, fazendo uma revolução, tornando o que era fácil, mais confortável, rápido e de baixo custo. Com o comércio eletrônico, a flexibilidade na compra é maior. Além de não precisar ir até a loja, há a facilidade de comprar de qualquer lugar. Para que a utilização do comércio eletrônico, portanto, seja feita de maneira segura, a literatura salienta que é necessário pesquisar, busca informações sobre a empresa vendedora e procurar ler comentários sobre as experiências de compras.

Albertin (2000) afirma que as empresas estão utilizando cada vez mais a infraestrutura da Internet e de suas aplicações, como meio para a realização de seus processos de negócio, com clara predominância daqueles relativos ao atendimento aos clientes. As empresas estão cada vez mais, se favorecendo do comércio eletrônico, entendendo a importância para seu crescimento e ganho de espaço no mercado, pois o comércio eletrônico abre novas possibilidades de negócios que seriam impensáveis (DINIZ, 1999). Porém, ainda existem muitas empresas que não aderiram, seja por falta de preparo ou por ser uma empresa de pequeno porte, e assim, vêm perdendo espaço no mercado.

Ainda segundo Carvalho (2010), o Business-to-Business (comércio eletrônico entre empresas), entre fornecedores como, por exemplo, fábricas vendendo para distribuidores, prestação de serviços entre empresas, no Brasil, segundo a E-Consulting, em 2004, as transações realizadas pela Internet foram de aproximadamente 36,7 bilhões de reais.

Guerreiro (2006) expõe que o comércio eletrônico, no geral, possui algumas características importantes: a comunicação, realizada através da troca de informações à distância entre consumidores e fornecedores; os dados: o gerenciamento de informações desempenha um papel importante no que diz respeito em criar e manter informações de diversos tipos de clientes através de bases de dados; a segurança: está é sem dúvida, uma característica fundamental, pois trata-se de garantir a integração e a privacidade na troca de informações, durante as transações. Por ser à distância, por exemplo, o consumidor precisa ter a garantia de que seus dados não serão usados para outros fins ou por terceiros.

Para a coleta de dados das transações dos clientes existem softwares específicos para isso, e a segurança, muito discutida, é a mais importante, por buscar proteger a privacidade das pessoas.

No contexto brasileiro, para Albertin (2000, p.100) "o comércio eletrônico no mercado brasileiro está consolidado e apresenta claros sinais de evolução, mesmo que ainda possa ser considerado em um estágio intermediário de expansão". As empresas sempre buscam um diferencial. E, considerando suas características e a grande evolução do comércio eletrônico no Brasil, os investimentos feitos têm sido boas estratégias para a competitividade empresarial.

Contudo, há avanços a serem concretizados. Entre alguns estudos no contexto brasileiro, o trabalho de Santarosa (2016) buscou por meio de um estudo de casos múltiplos, identificar quais aspectos são negligenciados em situações de fracasso por inatividade no Comércio Eletrônico (CE) de uma loja virtual considerada inovadora. Assim, foram analisadas três empresas varejistas nacionais com iniciativas de $\mathrm{CE}$, porém que convivem com a inatividade em suas lojas virtuais. São elas: a Pégasos, A Esportiva e a MXT. Todas foram consideradas inovadoras, seja sob a perspectiva da inovação de marketing, de processos ou organizacional. Entendendo-se a inatividade como um estado de subutilização do site por parte dos potenciais clientes, conceituou-se a inatividade no CE como um tipo de fracasso, pois o tráfego de visitantes registrado mostrou-se nos três casos, insuficiente para o sucesso no atingimento dos objetivos das empresas. Por fim, foi afirmado no estudo, que a inatividade no CE pode ser associada à inobservância dos aspectos de gestão, $\mathrm{RH}$, investimentos, tecnologia e mercado na condução de iniciativas inovadoras.

Perspectivas em Gestão \& Conhecimento, João Pessoa, v. 7, n. 1, p. 98-111, jan./jun. 2017. 
Mesmo assim, o interessante é que segundo a redação do site E-commerce Brasil (2015), dados da E-bit mostram que o faturamento do setor com vendas de bens de consumo foi de $\mathrm{R} \$ 35,8$ bilhões. O que representa um crescimento de $24 \%$ em relação ao ano de 2014 , quando se vendeu um total de $R \$ 28,8$ bilhões. O comércio eletrônico vem conquistando cada vez mais clientes, pelo simples fato das compras serem feitas de qualquer lugar, incluindo sua casa, trabalho, uma comodidade.

Isto está relacionado com a mudança no perfil do consumidor. Torezani (2008) considera que são essencialmente dois possíveis fatores que motivam as pessoas da "geração internet" a mudar de comportamento de compra: a conveniência da compra online, principalmente nas grandes cidades e localidades afastadas dos centros distribuidores, somado à economia de recursos, pois geralmente o preço dos produtos na internet é menor que o praticado nas lojas físicas.

Nesse contexto, o estudo de Moreira (2015) se propôs a analisar quais os fatores determinantes na escolha do tipo de loja por parte do consumidor quando comparada a loja online com a física. Concluiu-se que os consumidores preferem a loja física, mas não descartam a possibilidade de num futuro próximo vir a experimentar, ou tornarem-se e-consumers. Sendo que os fatores mais valorizados na loja online, são a poupança de tempo, autonomia e comodidade, enquanto na loja física, correspondem à rapidez de resposta e diversidade da oferta.

Em outro estudo, os fatores que mais influenciam na decisão de compra virtual dos consumidores são principalmente o preço, facilidade de acesso, comodidade e a variedade de produtos (SOARES; BATISTA; SCANDIUZZI, 2015).

Segundo o E-commerce Brasil (2012), a empresa de tecnologia GroupM Next divulgou um estudo em que que $45 \%$ dos consumidores entrevistados deixariam de comprar em loja física para comprar em loja virtual, caso oferecesse um desconto menor que $3 \%$. E, com um desconto de $5 \%$, mais da metade $(60 \%)$ optaria pela compra online. Se o desconto fosse de $20 \%$, esse índice aumentaria para quase $90 \%$.

No que diz respeito aos ganhos para os consumidores nas compras eletrônicas, segundo Castro (2011), trata-se de proporcionar compras mais eficientes, oferecendo um maior leque de escolhas, preços mais baixos e um nível de serviços personalizados. Também oferecem novos tipos de produtos e serviços.

Lourenzani, Pereira Filho e Silva (2001) destacam os benefícios do processo eletrônico de compras: a rapidez na transação, a flexibilidade e a eficiência desse processo, o alcance a grandes públicos e os menores custos de venda e distribuição. Ainda segundo Castro (2011), o consumidor passa a ter uma fonte de informação constante sobre novos tipos de produtos, podendo comparar preços, prazos de entrega, encontrar informações sobre as empresas, produtos e concorrentes, gerando a possibilidade de verificar suas vantagens, características, preços, rede de assistência técnica, entre outros benefícios.

\section{O PROCESSO DE COMPRA ELETRÔNICA}

Todas as compras pela internet passam por uma série de processos. Morais (2012) define o processo de compra assim: o cliente escolhe o produto desejado, pesquisa sobre ele para obter todas as informações necessárias, sendo que o contato vai ser através de foto e informações disponibilizadas. Para não evitar decepções, recomenda-se que se faça uma busca em mais sites para tirar dúvidas sobre determinado produto. Indispensável também seria uma busca em detalhes dos sites mais confiáveis, bem como de melhores preços.

Percebe-se que são basicamente os mesmos processos, com pequenas variações.

Segundo Guerreiro (2006), com a globalização o consumidor fica mais exigente quanto à qualidade do produto e principalmente quanto ao serviço prestado pelas empresas. Com isso,

Perspectivas em Gestão \& Conhecimento, João Pessoa, v. 7, n. 1, p. 98-111, jan./jun. 2017. 
as empresas estão cada vez mais se preocupando com a entrega do pedido, pois a agilidade é fundamental nos negócios. Sendo assim, para garantir o prazo de entrega e, ao mesmo tempo, a fidelização do cliente, é necessário que as empresas encarem a logística como uma atividade estratégica.

Sobre o processo de pagamento utiliza-se neste processo, formas de pagamentos digitais criados e reconhecidas internacionalmente pelos governos e órgãos relacionados. (AZEVEDO; ODONE; COELHO, 2014). O que tem conferido mais segurança nas transações.

\section{SEGURANÇA NAS COMPRAS ELETRÔNICAS E OUTROS FATORES}

Como já previa Diniz (1999), a velocidade e o alcance da consolidação das compras eletrônicas dependem da superação de obstáculos de vários tipos. Existem os obstáculos tecnológicos, como a dificuldade para desenvolvimento de ferramentas adequadas à transação online; os culturais, como a modificação de hábitos de consumo; os organizacionais, pela adaptação das empresas ao novo ambiente e até a superação dos obstáculos estruturais da sociedade, o que poderia criar condições para um ambiente de confiança, necessárias para o desenvolvimento do comércio eletrônico.

Como a internet consiste em vários computadores interligados, os riscos das compras eletrônicas são altos, e as falsificações estão por toda parte, por isso os riscos para o consumidor são grandes. Segundo Albertin e Moura (1998), a adoção do comércio eletrônico ainda está associada à cultura e, principalmente, ao que esse sistema irá oferecer para que tais transações sejam realizadas de forma consolidada e possam ser praticadas de forma segura. Segundo pesquisas recentes, uma das maiores preocupações dos executivos de (tecnologia da informação) Tl é em relação à segurança.

Observa-se que a falta de segurança no comércio eletrônico tem gerado muitas fraudes. Segundo Turchi (2010), o índice de fraudes no comércio eletrônico no Brasil e no mundo gira em torno de $1,2 \%$ do total das receitas do setor. No cenário internacional, há países que evitam transacionar com outros, segundo pesquisa da empresa americana CyberSource, devido aos altos índices de fraudes.

Interessante observar o estudo de Fonseca (2014), que visou identificar os riscos percebidos pelos consumidores portugueses nas compras online, aplicando um questionário a 182 indivíduos. Concluiu-se que, em relação ao grau de escolaridade, os consumidores com formação acadêmica revelaram uma percepção de risco maior, em relação aos de formação inferior.

Nesse cenário, talvez o maior desafio seja o estabelecimento da confiança inicial, em que o consumidor não possua nenhuma experiência de compra com a empresa e esta não possua informações sobre o consumidor (FEITOSA; GARCIA, 2015). Segundo Guerreiro (2006), apesar das vantagens, o comércio eletrônico apresenta alguns problemas que precisam ser superados, tais como:

a) Fraude: mesmo com as Vendas online crescendo a cada ano, ainda há muito medo por parte das pessoas, as quais utilizam a Internet somente como forma de consulta e não para a compra. Isso por insegurança, já que são muitas as informações que disponibilizam ao efetuar as compras. Vale ressaltar que os sistemas de criptografia estão reduzindo esse problema, de forma significativa.

b) Confidencialidade: a troca de informações entre fornecedores e compradores torna-se mais vulnerável por terceiros, que podem utilizá-las para outras finalidades, sem autorização.

c) Confiança: por ser uma negociação à distância, tanto o cliente quanto a empresa correm riscos, pois não sabem se as informações trocadas são verdadeiras. 
Segundo uma pesquisa realizada pelo site E-commerce Brasil (2014), uma em cada quatro pessoas prefere sair de casa para comprar em lojas físicas, em vez de utilizar a internet. Isso porque todos os sites de compras online solicitam, entre outros documentos, o número do cartão de crédito para concluir as transações.

Isso acaba gerando insegurança nos compradores e prejuízo para os comerciantes. Ainda que exista várias maneiras de perceber quais sites são não confiáveis. Existem aqueles que não tomam os cuidados necessários, gerando, consequentemente, o medo e a insegurança (E-commerce Brasil, 2014).

Assim, há ainda grandes desafios a serem superados pelas empresas, as quais precisam realizar os investimentos necessários, pois precisam estar inseridas nesse novo modelo de negócios, sob pena de perderem a competitividade.

Nesse sentido, os consumidores não podem descuidar ao comprar produtos ou serviços pela internet, mesmo com as empresas adotando formas seguras de acesso a dados, porque existem diversos programas maliciosos criados por pessoas com vasto conhecimento em informática, interessadas em receptar, ou melhor, roubar informações pessoais de organizações e de seus clientes visando usar em benefício próprio. (AZEVEDO; ODONE; COELHO, 2014).

Segundo Nakamura (2011), a segurança vem se tornando um tema importante no cotidiano das pessoas. Grandes investimentos estão sendo destinados à manutenção e melhorias dos sistemas de segurança, a fim de garantir o funcionamento perfeito dos sistemas online, como sites de comércio eletrônico, Internet Banking e outros serviços. Filadoro (2009) considera que cada vez mais o relacionamento virtual transforma o ambiente da empresa, por isso há a necessidade de maior atenção.

No que diz respeito à falta de segurança, as informações dos clientes devem ser protegidas, pois eles precisam ter a segurança de que haverá sigilo. Os clientes que realizam suas compras pela internet não querem ter problemas com dados pessoais. Se isso acontecer, e o cliente identificar que foi via site de comércio eletrônico, o fato poderá ser noticiado nas redes sociais e o site sofrerá uma reputação negativa.

Mesmo as compras eletrônicas em alta, ainda existem muitas inseguranças e dúvidas para aqueles que já realizaram suas compras e para quem nunca realizou. "A preocupação com segurança foi referência no discurso de $100 \%$ dos entrevistados dos não clientes e $90 \%$ dos usuários clientes", segundo pesquisa de Castro Neto et al., (2010, p. 19).

Já Filipini (2005) explana sobre a certificação, e diz que uma questão central para o usuário é ter certeza de que está transacionando com a loja correta, ou seja, não está trocando informações com o clone de um site conhecido. Para isso, existe o processo de certificação, no qual empresas conhecidas como "autoridades certificadoras" desempenham papel semelhante ao do cartório de registro. Elas vão certificar a identidade do processo de troca de chaves pública e privada, mas o que o usuário vê é um selo que atesta a identidade do site e garante que ele está trocando informações com a empresa correta. A certificação pode ser obtida diretamente da autoridade certificadora ou indiretamente pelo seu fornecedor de hospedagem.

Percebe-se que existem formas do cliente ter a certificação e se está fazendo negócios ou realizando compras em uma empresa confiável. Esse processo tem por função mostrar aos usuários uma espécie de selo, garantindo um processo mais confiável.

\section{METODOLOGIA DA PESQUISA}

Perspectivas em Gestão \& Conhecimento, João Pessoa, v. 7, n. 1, p. 98-111, jan./jun. 2017. 
Em seguida são apresentados os métodos e os caminhos utilizados para a realização desta pesquisa. Este estudo foi realizado tendo como público-alvo um grupo de consumidores do Vale do São Patrício, das cidades de Rubiataba e Nova América, estado de Goiás. Tais consumidores foram escolhidos de acordo com os parâmetros da amostra não probabilística por conveniência.

Sobre a região do Vale do São Patrício, esta se situa no estado de Goiás. É constituída por 22 municípios e tem sua sede em Ceres, cidade mais importante da região (EMATER, 2011).

Foi realizado um estudo exploratório. Rodrigues (2007) afirma que a pesquisa exploratória tem o objetivo de identificar inicialmente o problema, sua classificação e sua definição. Por outro lado, a partir da pesquisa bibliográfica construíram-se toda a fundamentação e os estágios da pesquisa. Para Andrade (2010), a pesquisa exploratória é o primeiro passo de todo trabalho cientifico, pois visa proporcionar maiores informações sobre determinado assunto; facilitar a delimitação de um tema de trabalho; definir os objetivos ou formular as hipóteses de uma pesquisa ou descobrir novo tipo de enfoque para o trabalho pretendido. Percebe-se que a pesquisa exploratória pode ser considerada fator chave para que se possa chegar a um determinado resultado.

Optou-se pela pesquisa de natureza qualitativa, particularmente útil para determinar os pontos principais da pesquisa. Esse tipo de pesquisa identifica as questões-chaves e permite formular perguntas, chegando às conclusões buscadas (MORESI, 2003). A pesquisa qualitativa parte dos motivos das coisas, suas razões, opiniões pessoais, buscando identificar perguntas que proporcionem uma melhor resposta, chegando assim às conclusões.

Para a coleta de dados, optou-se pelo questionário, contendo 11 perguntas. A elaboração do questionário foi pensada para que não tomasse muito tempo dos informantes. Foi estruturado com perguntas mais diretas, objetivas e claras, explorando as ideias e conceitos do Comércio Eletrônico, visando obter dos pesquisados suas opiniões e experiências. Foram aplicados 30 questionários, contendo em sua parte introdutória, as instruções quanto à pesquisa e seus objetivos. O questionário tinha a maior parte das perguntas fechadas, mas com algumas subjetivas. Os instrumentos foram aplicados para pessoas com a faixa etária a partir dos 16 anos, entre os dias 15 e 18 de dezembro de 2014. Foram escolhidos consumidores que tivessem realizado alguma compra eletrônica nos últimos seis meses.

A análise dos dados foi realizada a partir de uma análise cuidadosa dos questionários aplicados, os quais foram devidamente analisados para que fossem interpretados e representados. A análise dos dados foi realizada utilizando a Tabulação Manual, a técnica da Análise de Conteúdo e a representação gráfica, para se chegar aos resultados a seguir.

\section{RESULTADOS E DISCUSSÕES}

A seguir são apresentados os resultados desta pesquisa. Foram expostas e discutidas as opiniões e experiências dos respondentes em relação ao comércio eletrônico. Ao todo, 30 pessoas responderam aos questionários, as quais foram orientadas a responder com sinceridade e responsabilidade, para que a pesquisa tivesse maior confiabilidade.

Inicialmente, constatou-se que $70 \%$ dos respondentes da pesquisa são do sexo feminino e $30 \%$ do masculino. A maior parte dos respondentes, $57 \%$, está na faixa etária entre 20 e 30 anos.

Dos 30 participantes da pesquisa, $83 \%$ já realizaram compras pela internet. Observa-se que essa porcentagem é significativa. Isto vai de encontro à literatura pertinente, a qual afirma que o comércio eletrônico tem avançado no Brasil. Para Castro (2011), o fato do grande número de pessoas realizarem compras pela internet é devido à maior possibilidade de escolhas, pelo fato do processo proporcionar compras mais eficientes, oferecendo um leque

Perspectivas em Gestão \& Conhecimento, João Pessoa, v. 7, n. 1, p. 98-111, jan./jun. 2017. 
de escolhas, preços mais baixos e um nível de serviços personalizados. Já Lourenzani, Pereira Filho e Silva (2001), destacam a rapidez e a eficiência, como motivos dos internautas realizarem as compras de forma eletrônica.

Foi questionado aos respondentes, os motivos pelos quais deixariam de realizar suas compras pela internet. A grande maioria, $80 \%$, responderam que seria por não ter contato físico com o produto e por não poder tocar e conferir a qualidade do produto. E, $20 \%$ apontaram o medo de informar dados pessoais e sofrerem fraudes. Segundo uma pesquisa realizada pelo site E-commerce Brasil (2014), o medo e a insegurança de fornecer os dados pessoais em sites de compras, ainda é uma barreira para o crescimento do comércio eletrônico. Já Albertin e Moura (1998) afirmam que esse fato está muito relacionado à cultura existente, pois muitos ainda preferem ir até a loja física e conferir o produto, mesmo que isso custe mais. Essas questões foram mencionadas por Diniz (1999).

Todos os respondentes que realizaram suas compras pela internet receberam o pedido em conformidade ao que era esperado. Isso vai de encontro à fala de Guerreiro (2006), que afirma que as empresas estão se preocupando mais com a fidelização dos clientes, por isso os serviços prestados devem ser de qualidade, desde o atendimento até a entrega do produto, garantindo a satisfação do consumidor.

Dos respondentes, $88 \%$ afirmaram que não tiveram problemas com compras pela internet. Apenas $12 \%$ afirmaram ter tido problemas, relacionados ao atraso na entrega e que a quantidade recebida era inferior à pedida, mas que logo o problema foi solucionado. Sabe-se que ainda assim existem esses tipos de erros, os quais podem prejudicar a empresa vendedora, pois os clientes podem expressar suas insatisfações, até mesmo nas redes sociais, o que prejudicaria a imagem da empresa.

Dos respondentes que afirmaram ter tido problemas (12\%) nas compras pela internet, $67 \%$ voltaram a realizar compras virtuais. $E$, apenas $33 \%$ não voltaram a fazer esse tipo de transação.

Quanto às vantagens das compras eletrônicas, $56 \%$ das opiniões apontaram a vantagem dos preços mais baixos. Em seguida, $24 \%$ das pessoas apontaram a facilidade nas pesquisas dos produtos. Logo em seguida, ficou a vantagem de comprar em qualquer lugar e a qualquer momento, sendo $16 \%$. Com $4 \%$, apareceu a comodidade e a conveniência que o comércio eletrônico oferece.

Percebe-se o preço baixo como fator motivador é predominante, que mais influencia na hora dos internautas decidirem por uma compra online. Castro (2011) afirmou que uma das grandes vantagens do comércio eletrônico são os preços mais acessíveis. Segundo a redação do E-commerce Brasil (2012), muitos consumidores deixariam de comprar em uma loja física se uma loja virtual oferecesse o mesmo produto, mas com preço menor. O E-commerce Brasil mostrou que com um desconto de $5 \%$, mais da metade dos participantes de uma pesquisa, (60\%), optaria pela compra online. Se o desconto fosse de $20 \%$, esse índice aumentaria para quase $90 \%$ das intenções de compra.

Em seguida, o Gráfico 1 apresenta a frequência com que os pesquisados realizam compras pela internet. O resultado ficou dividido, pois 36\% compram apenas em grandes promoções; com $24 \%$, os que compraram apenas uma vez e os que compram mensalmente; em seguida aparece os que compram apenas em datas comemorativas, sendo $12 \%$ dos respondentes; e por último, $4 \%$, são os que realizam as compras apenas anualmente.

Gráfico 1 - Frequência com que realiza compras pela internet 


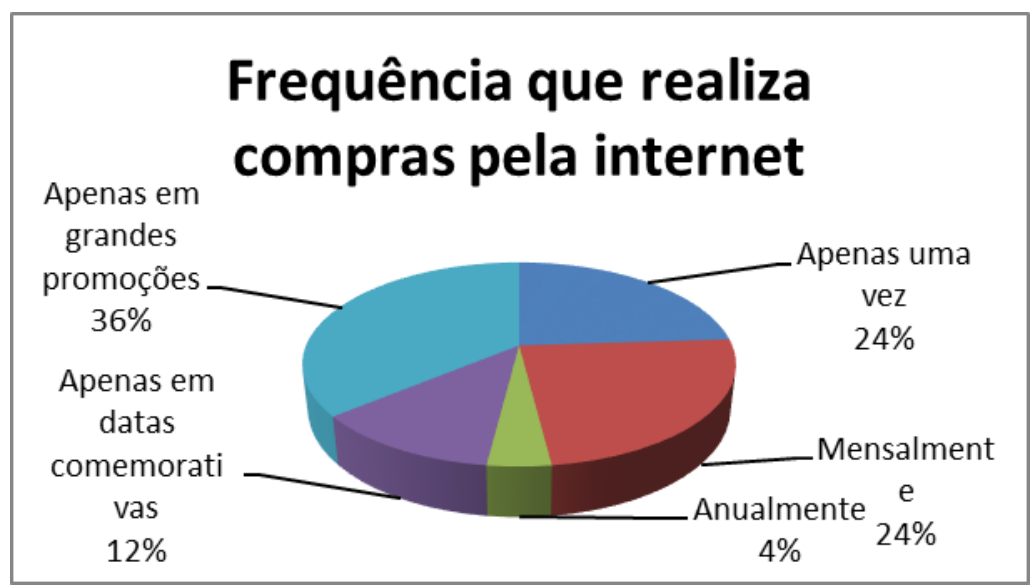

Fonte: Dados da pesquisa, 2014

Este Gráfico reforça mais a questão dos preços dos produtos ofertados. Esse é um dos grandes motivos para a decisão de compra da maioria dos pesquisados. Parece que muitos consumidores ainda esperam as promoções para efetuarem suas compras.

Uma das perguntas feitas foi para identificar o que impede o crescimento do comércio eletrônico no Brasil na percepção dos pesquisados. Sabe-se que, mesmo com o desenvolvimento do comércio eletrônico no Brasil ser crescente, ainda há muito para avançar. Obteve-se com $57 \%$ das respostas, que a falta de segurança é o que impede o crescimento do comércio eletrônico no Brasil. Em seguida, com 20 \%, a dificuldade em fazer a devolução do produto, caso necessário. Logo depois, aparece a dificuldade em navegar nos sites e concluir as compras, com $13 \%$. E por último, com $10 \%$, foi apontada a falta de um atendente para explicar sobre o produto. Sem dúvida, a falta de segurança sentida pelo consumidor, ainda é o que mais embaraça o desenvolvimento do comércio eletrônico no Brasil.

Como Guerreiro (2006) já havia afirmado, mesmo com as vantagens do comércio eletrônico, a questão da segurança ainda é um problema, envolvendo as fraudes, portanto, a necessidade da confidencialidade e a falta de confiança são pontos decisivos no momento da compra. Já Filadoro (2009) afirma que isso se deve ao expressivo crescimento do ambiente virtual e que as empresas devem se preparar, sem deixar de lado a segurança. Nesse sentido, foi afirmado por Turchi (2010), que há um ranking de países menos seguros, no qual o Brasil figura em sétimo lugar. Mas as empresas, de modo geral, estão buscando tornar a segurança uma de suas prioridades. Segundo Nakamura (2011), nos últimos anos, a segurança vem se tornando um tema importante no cotidiano das empresas e assim investimentos estão sendo destinados à manutenção e melhorias dos sistemas de segurança.

Em se tratando da influência das redes sociais em suas decisões de compras, os respondentes, a maior porcentagem com $56 \%$, foi daqueles que não compraram através de anúncios da Web. 44\% são os que compraram a partir desses anúncios. Apesar deste último percentual, percebe-se a grande influência dos anúncios nas redes sociais. Segundo Almeida Junior (2007), isso se deve ao fato de que as redes sociais são um canal eficiente de acesso às lojas virtuais, que influencia os internautas à realizarem suas compras. E, Moro (2012) afirma que as redes sociais oferecem uma oportunidade relevante para as empresas divulgarem suas marcas e promoções.

Por fim, vale ressaltar que as compras eletrônicas é uma oportunidade para as empresas melhorarem sua competitividade (DINIZ, 1999). Embora existam ainda muitos desafios a serem superados, principalmente no que diz respeito à questão da segurança nas transações eletrônicas.

Perspectivas em Gestão \& Conhecimento, João Pessoa, v. 7, n. 1, p. 98-111, jan./jun. 2017. 


\section{CONSIDERAÇÕES FINAIS}

Esta pesquisa teve como objetivo identificar o posicionamento e a experiência de compra de alguns consumidores, residentes no Vale de São Patrício, estado de Goiás, no que diz respeito ao comércio eletrônico, bem como se busca ainda destacar os fatores que podem ser considerados como oportunidades e desafios para as empresas que adotam essa modalidade de vendas.

Sabe-se que a internet e as organizações virtuais se tornaram indispensáveis para as pessoas do mundo todo, de forma que possam realizar com maior comodidade suas tarefas, compras, distração, negócios e diversão. Indo de encontro aos estudos de Testa e Luciano (2008), isso tem contribuído para um melhor relacionamento com o cliente e ganho de espaço nos mercados, no que diz respeito ao comércio eletrônico. O grande número atual de internautas, que tende a crescer, conectados a todo o momento é o ponto central para o sucesso desse tipo de comércio. As oportunidades de negócios, via forma eletrônica, não se limitam a vendas diretas por meio de uma única loja virtual, mas por diversas integrações como serviços móveis, TV digital, Personal Digital Assistants (PDAs) e outros, dadas as oportunidades que o ambiente virtual proporciona (SANTOS; ARRUDA FILHO, 2014).

Nesta pesquisa, percebeu-se a quantidade de pessoas que utilizam o comércio eletrônico ao realizarem suas compras é significativa, e vem crescendo, apesar dos respondentes afirmarem que compram mais quando há promoções nas lojas virtuais. $E$, um fator que motiva os consumidores é o preço mais baixo dos produtos, em comparação às ofertas das lojas físicas.

Foram observadas também as desvantagens do comércio eletrônico para o consumidor, relacionadas à falta de segurança. Isto impede que o comércio eletrônico possa alcançar um número maior de adeptos. A falta de segurança foi o fator mais apontado entre os pesquisados, pois $57 \%$ apontaram a falta de segurança como o principal fator impeditivo para a realização das compras. Nesse sentido, os estudos de Feitosa e Garcia (2015) apontam que devido a necessidade de se conhecer mais o comerciante antes da decisão de compra, isso incentivou a criação de sistemas de identificação da reputação, cujos serviços desempenham um papel relevante no comércio eletrônico. Esses sistemas de reputação visam à redução da assimetria de informações entre consumidores e vendedores, além de atuarem no estabelecimento de selos e escores que atestam o cumprimento de normas necessárias às lojas que atuam no mercado digital.

Percebe-se que o comércio eletrônico traz grandes vantagens e facilidades para o consumidor. Vale ressaltar que a maioria dos respondentes desta pesquisa que já realizou compras pela internet recebeu o pedido em conformidade ao que era esperado. Mas, há ainda algumas barreiras a serem superadas por parte das empresas, principalmente relacionadas à segurança nas transações.

Notou-se que a questão cultural, como a necessidade de poder tocar o produto e conferir sua qualidade é outro fator que dificulta as transações do comércio eletrônico. Pois o que o cliente tem para avaliar sobre os produtos ofertados são as fotos ilustrativas e os informativos da empresa vendedora. Para alguns, isso ainda não é um fator de desconfiança, uma vez que precisam do toque para ter a certeza que o produto está de acordo com suas necessidades. Para outros, a navegação do site ainda é um problema para a finalização da compra, pois encontram dificuldades e acreditam que alguns sites são confusos, desde a identificação do produto até a finalização da compra, gerando dúvidas, chegando até mesmo à desistência da compra.

Enfim, o fato é que o comércio eletrônico representa uma evolução social e tecnológica e traz mudanças estruturais no que diz respeito ao processo de troca. Sendo assim, as empresas devem, cada vez mais, aprimorar seus processos e suas lojas virtuais.

Perspectivas em Gestão \& Conhecimento, João Pessoa, v. 7, n. 1, p. 98-111, jan./jun. 2017. 
Entre as limitações do estudo realizado: as conclusões foram baseadas em uma amostra não muito representativa, de modo que alguns resultados encontrados podem não refletir a realidade de outros consumidores de outras regiões brasileiras, o que constitui uma limitação típica de estudos dessa natureza.

\section{REFERÊNCIAS}

ALBERTIN, A. L. Comércio eletrônico: modelo, aspectos e contribuição da sua aplicação. $2 \underline{a}$ ed. São Paulo: Atlas, 2004.

O comércio eletrônico evolui e consolida-se no mercado brasileiro. Revista de Administração de Empresas- RAE, São Paulo, v. 40, n. 4, 2000, p. 94-102.

ALBERTIN, A. L.; MOURA, R. M. Comércio eletrônico: seus aspectos de segurança e privacidade. Revista de Administração de Empresas - RAE, São Paulo, v. 38, n. 2, 1998, p. 49-61.

ALMEIDA JR., E. Comércio eletrônico (e-commerce), 1998. Disponível em: http://blog.segr.com.br/wp-content/uploads/2013/09/Com\%C3\%A9rcio-

Eletr\%C3\%B4nico.pdf. Acesso em: 12 nov. 2014.

ANDRADE, M. M. Introdução à metodologia do trabalho científico. 10a ed. São Paulo: Atlas, 2010.

AZEVEDO, Cristiano Oliveira; ODONE, Marcos Paulo; COELHO, Marcos Antônio Pereira. Estudo sobre a evolução do comércio eletrônico, suas formas de pagamentos digitais e suas preocupações quanto à segurança e a privacidade. XI EVIDOSOL e VIII Ciltec-Online, junho, 2014.

CAMPI, M. Comércio Eletrônico alcança 51,3 mi de consumidores no Brasil, 2014. Disponível em http://info.abril.com.br/noticias/mercado/2014/03/comercio-eletronico-alcanca-51-3-mide-consumidores-no-brasil.shtml. Acesso em: 12 nov. 2014.

CARVALHO, R. C. L. Negócios eletrônicos na modalidade B2C - Business to Consumer: um estudo de caso de uma empresa varejista de produtos eletroeletrônicos em Fortaleza. Trabalho de Conclusão de Curso (Graduação em Ciências da Computação) da Faculdade Lourenço Filho, Fortaleza-CE, 2010.

CASTRO, W. C. E-commerce: vantagens para consumidores e para as empresas. 2011. Disponível em:_http://www.oficinadanet.com.br/artigo/e-commerce/e-commerce--vantagenspara-consumidores-e-para-as-empresas. Acesso em: 10 dez. 2014.

CASTRO NETO, J. L.; YOSHITAKE, M.; FRAGA, M. S.; VASCONCELOS, Y. L. Comércio eletrônico: análise dos fatores críticos. Revista Business Review de Negócios, n. 9, 2010, p. 1-25.

DINIZ, Eduardo Henrique. Comércio Eletrônico: Fazendo Negócios por meio da Internet. RAC, v. 3, n. 1, Jan./Abr. 1999, p. 71-86. 
E-COMMERCE BRASIL. Maioria dos compradores abandonaria uma loja física se o preço na internet fosse $\mathbf{5 \%}$ menor. $2012 . \quad$ Disponível em: http://ecommercenews.com.br/noticias/pesquisas-noticias/maioria-dos-compradoresabandonaria-uma-loja-fisica-se-o-preco-na-internet-fosse-5-menor. Acesso em: 04 dez. 2014.

. Um em cada quatro brasileiros não compra pela internet por medo de fraudes, 2014. Disponível em: http://www.ecommercebrasil.com.br/noticias/um-em-cada-quatrobrasileiros-nao-compra-pela-internet-por-medo-de-fraudes/. Acesso em: 06 dez. 2014.

EMATER -Região Vale do São Patrício. 2011. Disponível em: http://www.emater.go.gov.br/w/543. Acesso em: 05 jan. 2015.

FEITOSA, Douglas de Lima. GARCIA, Leandro Sumida. Sistemas de Reputação: Um Estudo sobre Confiança e Reputação no Comércio Eletrônico Brasileiro. RAC, Rio de Janeiro, v. 20, n. 1, art. 5, Jan./Fev. 2015, p. 84-105

FILADORO, A. Como aumentar o comércio eletrônico com segurança?_Revista iMasters, 2009, disponível em: http://imasters.com.br/artigo/13097/e-commerce/como-aumentar-ocomercio-eletronico-com-seguranca/. Acesso em: 25 mar. 2015.

FILIPINI, D. Segurança na internet: tudo sobre Comércio Eletrônico. 2005. Disponível em: http://www.e-commerce.org.br/artigos/seguranca internet.php. Acesso em: 08 dez. 2014.

FONSECA, Luis Filipe Matos. Riscos percebidos pelos consumidores portugueses nas compras online. Dissertação de mestrado apresentada a escola superior de Aveiro, IPAM The Marketing School, 2014.

GUERREIRO, A. S. Análise da Eficiência de Empresas de Comércio Eletrônico usando Técnicas da Análise Envoltória de Dados. 2006. Dissertação apresentada ao Programa de PósGraduação em Engenharia de Produção do Departamento de Engenharia Industrial da PUCRio, RJ, 2006.

LOURENZANI, A. E. B. S.; PEREIRA FILHO; N. A., SILVA, A. L. 2001. Utilização de comércio eletrônico na comercialização de hortícolas: um estudo de caso, TCC (Graduação) - Faculdade de Economia, Administração e Contabilidade de Ribeirão Preto-SP, 2001.

MORAIS, F. Processo de compra on-line, 2012. Disponível em: http://www.ecommercebrasil.com.br/artigos/o-processo-de-compra-online/ Acesso em: 10 nov. 2014.

MOREIRA, Sara Patrícia dos Santos. Fatores determinantes na escolha do consumidor: o caso das lojas físicas e online do hipermercado Continente. 2015. Dissertação de Mestrado apresentada ao Instituto de Contabilidade e Administração do Porto, Instituto Politécnico do Porto, 2015.

MORESI, E. Metodologia da pesquisa. PRPG Universidade Católica de Brasília-DF, 2003.

MORO, A. A importância das redes sociais para e-commerce. CiaShop, 2012. Disponível em: http://www.ciashop.com.br/noticias/a-importancia-das-redes-sociais-para-e-commerce/.

Acesso em: 08 nov. 2014.

NAKAMURA, A. M. Comércio eletrônico riscos nas compras pela internet. Trabalho de Conclusão de Curso (Graduação) da Faculdade de Tecnologia de São Paulo, 2011. 
RODRIGUES, W. C. Metodologia científica. Revista UNISC, Universidade de Santa Cruz do Sul, Paracambi, 2007.

SANTAROSA, Rosana. A Inatividade das lojas Virtuais: uma Análise do Comércio Eletrônico à Luz da Inovação. Dissertação apresentada à Escola de Administração de Empresas de São Paulo, da Fundação Getúlio Vargas. São Paulo, 2016.

SANTOS, Agenilson Jonatan Corrêa; ARRUDA FILHO, Emilio Jose Monteiro. Comportamento Utilitário Hedônico do Consumidor Tecnológico: E-commerce com ambiente da escolha. $R$. Adm. FACES Journal, Belo Horizonte v. 13 n. 2, p. 99-121, 2014.

SEBRAE - SERVIÇO BRASILEIRO DE APOIO ÀS EMPRESAS. Comércio eletrônico, 2009._Disponível em: http://www.sebraepr.com.br/StaticFile/Portallnternet/img/cartilha com eletronico.pdf. Acesso em: 10 jun. 2014.

SOARES; Carlos H. Hentz; BATISTA, Lucas Pelegrinelli B.; Fernando, SCANDIUZZI. Comércio eletrônico: fatores que estimulam e desestimulam os consumidores. Rev. Científica Eletrônica UNISEB, Ribeirão Preto, v.5, n. 5, p.34-52, jan./jun. 2015.

TESTA, Maurício Gregianin; LUCIANO, Edimara Mezzomo. Vantagens e Características das lojas físico-virtuais: o caso da Colombo Virtual Shop. REAd - Edição 59 v. 14, n. 1, 2008.

TOREZANI, N. O crescimento do e-commerce no Brasil. Revista iMasters, 2008. Disponível em: http://imasters.com.br/artigo/9649/e-commerce/o-crescimento-do-e-commerce-no-brasil/. Acesso em: 05 dez. 2014.

TURCHI, S. O comércio nas redes sociais. Revista Pequenas Empresas \& Grandes Negócios, 2010. Disponível em: http://revistapegn.globo.com/Revista/Common/0,EMI209214-17141,00O+COMERCIO+NAS+REDES+SOCIAIS.html2011. Acesso em: 25 mar. 2015. 